\title{
ARTICLES
}

\section{KNOWLEDGE REGARDING KANGAROO MOTHER CARE AMONG LINK WORKERS}

\section{Dr. Arundeep Kaur* I Mrs Shiva Sharma**}

*Associate Professor, CKD International Nursing College, Amritsar, Punjab, India.

**Nursing Tutor, Chief Khalsa Diwan, International Nursing College, Amritsar, Punjab, India.

DOI: http://doi.org/10.47211/tg.2020.v07i03.002

\section{ABSTRACT}

Mother is one who gives birth of a baby, who cares for the baby and protects her baby from any harm. Kangaroo mother care is the method of care for all new born but particularly for premature babies and it is a special way of caring of low birth weight babies and it fosters their health and well-being by promoting effective thermal control, breastfeeding, prevention of infection, bonding, physical, emotional support to mother and baby also early discharge from the hospital from the hospital from the hospital. Kangaroo mother care was started in Columbia in response to shortage of incubators and serve hospital infection. This study was conducted to assess the knowledge and provide structured teaching programme to link worker to gain knowledge about kangaroo mother care which help to reduce the neonatal mortality rate to certain extent. With kangaroo mother care, we can save the babies from hypothermia and also gives the chance to babies for survive and thrive. Result revealed that in pre-test knowledge majority of link worker i.e. 65\% were in below average group and 35\% were having average knowledge. After STP 70\% link workers came under good knowledge and 30\% were under average knowledge.

Key Words: Kangaroo mother care, link workers, birth baby.

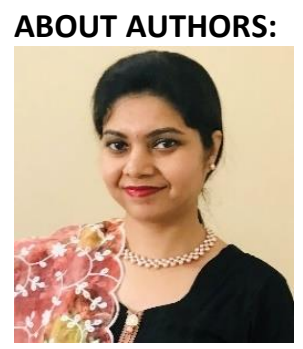

Dr. Arundeep Kaur is Associate Professor at Chief Khalsa Diwan International Nursing College in Amritsar. She is having 8 years of teaching experience. She has published case book in obstetrics, various articles and research papers in national and international journals.

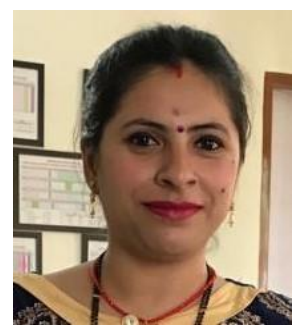

Mrs. Shiva Sharma is nursing tutor at Chief Khalsa Diwan International Nursing College in Amritsar. She has having 5 years of teaching experience. 


\section{ARTICLES}

\section{INTRODUCION}

Mother is one who gives birth of a baby, who cares for the baby and protects her baby from any harm. Kangaroo mother care is the method of care for all new born but particularly for premature babies and it is a special way of caring of low birth weight babies and it fosters their health and well-being by promoting effective thermal control, breastfeeding, prevention of infection, bonding, physical, emotional support to mother and baby also early discharge from the hospital from the hospital from the hospital. Kangaroo mother care was started in Columbia in response to shortage of incubators and serve hospital infection. According to Manoj Yadav (2012) Kangaroo mother care is a powerful, easy to use method to promote the health and wellbeing of low birth weight. I $t$ helps to improve growth and reduces infections. Improve mother infant bonding. All babies less than $2000 \mathrm{gm}$ weight are candidate for Kangaroo mother care.

WHO (2003) stated that approximately 20 million low birth weight babies are born each year, because of their preterm birth or impaired prenatal growth, mostly in less developed countries. Low birth weight and pre-term birth are thus associated with high neonatal and infant mortality and morbidity. Therefore, care of such infants becomes a burden for health and social system elsewhere. In affluent societies, the contributor to low birth weight in preterm birth. The rate has been decreasing due to better socio-Economic conditions, life style and nutrition. But in less developed countries it is prevailing due to lack of modern technology and shortage of skilled staff. For preterm infants prolonged medical care is important but due to lack of technology and shortage of skilled staff, it is not possible. However, kangaroo mother care is an effective way to meet babies' need for warmth, breast feeding, and protection from infection, stimulation, safety and love.

\section{OBJECTIVES}

1. To assess the pre-test knowledge regarding kangaroo mother among link worker.

2. To assess the post-test knowledge regarding kangaroo mother among link worker.

3. The compare the pre-test and post-test knowledge regarding kangaroo mother care among link worker.

4. To find the association of post-test knowledge with selected socio-demographic variables such as age, education, experience, marital status, religion.

\section{METHODS AND MATERIALS}

The research approach for this study was experimental. Attempt has been made to assess the effectiveness of structured teaching program on knowledge regarding Kangaroo Mother Care among link workers. Study was conducted on 20 link workers from PHC Centre Amritsar (Punjab) with purposive sampling technique a selfstructured questioner was proposed to assess the knowledge regarding kangaroo mother care. Tool included two parts, part A Socio demographic profile and part B self-structured questionnaire. Reliability of the tool was computed by spearman brown's prophecy formula. Analysis was done by using inferential statistics such as mean, percentage, standard deviation and t-test. Bar diagram were used to depict the finding of study.

\section{RESULTS}

\section{Objective 1:}

To assess the pre-test knowledge regarding kangaroo mother care among link workers.

\section{Table 1}

Pre-test knowledge score $\quad \mathrm{N}=20$

\begin{tabular}{|l|c|c|c|c|}
\hline \multicolumn{1}{|c|}{ Level of knowledge } & $\mathbf{N}$ & $\mathbf{\%}$ & Mean & SD \\
\hline Good $(>71 \%)$ & --- & --- & -- & -- \\
\hline Average (36-70\%) & 7 & 35 & 12.71 & 1.66 \\
\hline Below Average (<35\%) & 13 & 65 & 8.61 & 1.42 \\
\hline
\end{tabular}

Table 1 showed that in pre-test, out of 20 link worker majority i.e. $65 \%$ of link worker had below average knowledge followed by $35 \%$ average knowledge. 


\section{ARTICLES}

\section{Objective 2}

To assess the post-test knowledge regarding kangaroo mother care among link worker.

Table 2

Post-test knowledge score $\quad \mathrm{N}=20$

\begin{tabular}{|l|c|c|c|c|}
\hline \multicolumn{1}{|c|}{ Level of knowledge } & N & \% & Mean & SD \\
\hline Good (>71\%) & 14 & 70 & 24.21 & 24.10 \\
\hline Average (36-70\%) & 6 & 30 & 18 & 2.08 \\
\hline Below Average (<35\%) & -- & -- & -- & -- \\
\hline
\end{tabular}

Table 2 showed post-test knowledge, out of 20 link worker, majority $70 \%$ had good knowledge followed by average knowledge $30 \%$ and below average knowledge was nil.

\section{Objective 3}

To compare the pre-test and post-test knowledge kangaroo mother care among link worker.

Table 3

Comparison of pre-test and post-test knowledge score

\begin{tabular}{|l|c|c|c|c|}
\hline \multicolumn{1}{|c|}{ Level of knowledge } & Mean & S.D & Df & ' $\mathbf{t}$ \\
\hline Pre test & 8.67 & 5.008 & 19 & 9.140 \\
\hline Post test & 22.5 & 4.58 & & \\
\hline
\end{tabular}

Table 3 depict the comparison of pre-test and post-test knowledge level of link worker regarding kangaroo mother care. The post-test mean knowledge value i.e. 22.5 was higher than higher than pre-test mean knowledge value 8.67 in link worker regarding kangaroo mother care. The mean difference pre-test and post-test knowledge level was found statistically significant at $p<0.05$.

Hence, it can be concluded that structured teaching programme has significantly effective in increasing the knowledge of link worker regarding kangaroo mother care.

\section{CONCLUSION}

An evaluated study was conducted to assess the knowledge of link workers regarding kangaroo mother care in selected areas of Amritsar (Punjab). Two PHC centre were selected and data was collected from 20 link workers. An analysis was done and the following conclusions were drawn:

- Most of the link worker lacked prior knowledge of kangaroo mother care which was found to be increased after structured teaching programme on kangaroo mother care.

- It was evident from the overall improvement in the mean knowledge score of pre-test meant $\pm \mathrm{SD}=8.67 \pm 5.008$ and in the post test mean $\pm \mathrm{SD} 22.5 \pm 4.58$ with $\mathrm{t}$ value of 9.140 .

\section{REFERENCES}

1. Parul Dutta: Paediatric Nursing. Published by Jay Pee Edition, $2^{\text {nd }}$ Page. No. 109.

2. Meharban Singh. Care of the new born published by sagar, Edition $7^{\text {th }}$ page No. 204.

3. Piyush Gupt. Essential paediatric nursing, published by CBS, Edition $2^{\text {nd }}$, Page No. 45.

4. Vinod K Paul, Arvind Baga. Ghai essential Paediatrics. Edition $7^{\text {th }}$ Page. No. 117.

5. Manoj Yadav, text book of child health nursing. Published by R.K. Gupta, Edition 2012, Page No. 325.

6. Annanma Jacob, Comprehensive textbook midwifery and gynaecological nursing. Publisher Jaypee, Edition $3^{\text {rd }}$, Page No. 49.

7. Dutta DC, textbook of Obstetrics, $7^{\text {th }}$ Edition Kolkata: New Central Book Agency Publisher.

8. Kangaroo Mother Care. A practical guide. World Health Organization, 2003. Available from http:/www.who.int.maternalchild adolescent/documents/924159351/n

9. Workuji, Kassie. Effectiveness of structured teaching programme on knowledge and practice of Kangaroo mother care among link workers. Journal of Niaghtrigale, Nursing Time 2009; 4(I) 43-44.'

10. Feldman, knowledge and practices of kangaroo mother care among link workers. Journal of Nightrigale, Nursing Times 2002; 4(10):43-44. 